\title{
ANALISIS PRODUKTIVITAS MESIN PERCETAKAN PERFECT BINDING DENGAN METODE OEE DAN FMEA
}

\author{
Arif Rahman dan Surya Perdana \\ Jurusan Teknik Industri, Universitas Indraprasta PGRI, Jl. Nangka No. 58 C, Jakarta 12530 \\ e-mail: arif.rahman0876@gmail.com; suryaperdana.st.mm@gmail.com
}

\begin{abstract}
ABSTRAK
Mesin Perfect Binding merupakan alat finishing untuk proses menjilid buku yang sering digunakan pada industri percetakan. Ketika berproduksi masalah yang sering muncul pada mesin Perfect Binding adalah downtime, breakdown, setup and adjustment yang mengakibatkan produktivitas hasil produksi berkurang. Tujuan dalam penelitian ini adalah untuk meningkatkan produktifitas dengan cara mengetahui hasil perhitungan Overall Equipment Effetiviness (OEE) pada mesin Perfect Binding dan mengetahui beberapa faktor yang menjadi penyebab menurunnya produktivitas hasil produksi dengan menggunakan diagram sebab akibat dan metode Failure Mode and Effect Analysis (FMEA) sehingga dapat dilakukan langkah-langkah perbaikan. Berdasarkan perhitungan Overall Equipment Effetiviness (OEE) pada Mesin Perfect Binding, periode April-Juni 2016 dibandingkan dengan periode April-Juni 2017, didapatkan hasil terjadi peningkatan di bulan April 2017 sebesar 2,24\%, di bulan Mei 2017 sebesar 11,88\%, dan di bulan Juni 2017 sebesar 4,53\%. Secara umum pencapaian OEE meningkat tetapi belum mencapai kriteria World Class OEE. Rendahnya nilai OEE disebabkan oleh 4 faktor yaitu pengetahuan operator tentang mesin kurang (Manusia), temperatur lem tidak stabil (Mesin), vendor terlambat supply (Material), dan waktu ganti pisau tidak efisien (Metode).
\end{abstract}

Kata kunci: Overall Equipment Effectiveness, Failure Mode and Effect Analysis, Produktivitas.

\begin{abstract}
Perfect Binding Machine is a finishing tool for the book binding process that is often used in the printing industry. The Problems that usually occur during production are downtime, breakdown, setup and adjustment which results in decreased productivity. The purpose of this research is to increase productivity by knowing the results of the calculation of Overall Equipment Effetiviness (OEE) on the Perfect Binding machine and knowing several factors that cause the decline in productivity of production results using cause and effect diagrams and the Failure Mode and Effect Analysis (FMEA) method so repair steps can be done. Based on the calculation of Overall Equipment Effetiviness (OEE) on Perfect Binding Machines, the period April-June 2016 compared to the April-June 2017 period, the results showed an increase in April 2017 of 2.24\%, in May 2017 amounting to 11.88\%, and in June 2017 it was 4.53\%. In general, the achievement of OEE has increased but has not yet reached the OEE World Class criteria. The low value of OEE is caused by 4 factors: lack of operator knowledge about the machine (Human), unstable glue temperature (Machine), vendor late supply (Material), and inefficient knife change time (Method).
\end{abstract}

Keywords: Overall Equipment Effectiveness, Failure Mode and Effect Analysis, Productivity.

\section{PENDAHULUAN}

Diera digital ini banyak ditemukan sumber-sumber informasi bagi para pelajar dan masyarakat pada umumnya dalam bentuk e-paper atau e-book yang dapat diakses melalui perangkat elektronik berupa handphone. Meskipun begitu buku-buku dalam bentuk fisik masih cukup banyak peminatnya, buku-buku tersebut dengan mudah dapat kita jumpai di perpustakaan, di sekolah-sekolah maupun di toko-toko buku. Agar tetap eksis dan diminati para pembacanya, serta dapat tetap bersaing dalam industri percetakan (printing) maka masing-masing perusahaan percetakan harus berlomba-lomba dalam memberikan pelayanan terbaik kepada konsumen. Kualitas dan kerapihan suatu buku dapat menjadi daya tarik konsumen untuk membacanya. Kualitas tersebut dapat dilihat jelas pada bagian cetakan maupun pada bagian jilid sebuah buku. Mesin Perfect Binding merupakan suatu alat finishing untuk proses menjilid sebuah buku yang sering digunakan pada industri 
percetakan. Produktifitas mesin ini menjadi salah satu kekuatan dalam menghasilkan produk (mass production) guna memberikan kepuasan konsumen (service excellent).

Untuk itu dalam penelitian ini, mesin yang menjadi objek penelitian adalah mesin Perfect Binding yang digunakan pada perusahaan percetakan yang berada di daerah Jakarta. Ketika berproduksi masalah yang sering muncul pada mesin Perfect Binding adalah mesin yang mengalami banyak waktu terbuang (downtime), waktu berhenti (breakdown), dan persiapan peralatan (setup and adjustment) yang mengakibatkan produktivitas hasil produksi berkurang.

Tujuan dalam penelitian ini adalah untuk meningkatkan produktifitas dengan cara mengetahui hasil perhitungan Overall Equipment Effetiviness (OEE) pada mesin Perfect Binding dan mengetahui beberapa faktor yang menjadi penyebab menurunnya produktivitas hasil produksi dengan menggunakan diagram Sebab Akibat dan metode Failure Mode and Effect Analysis (FMEA) sehingga dapat dilakukan langkah-langkah perbaikan.

Total Productive Maintenance (TPM) merupakan suatu konsep yang bertujuan untuk mencapai tingkat efisiensi tertinggi pada suatu sistem produksi (efisiensi menyeluruh), menciptakan sistem "tanpa kecelakaan dan tanpa produk cacat", dengan tujuan life cycle dari sistem produksi. Sasaran utama Total Productive Maintenance adalah Zero ABCD, yaitu Zero Accident yaitu sistem yang aman dan ramah lingkungan. Zero Breakdown akan tercapai apabila perusahaan dapat melakukan pencegahan terjadinya kerusakan mesin secara terus menerus. Dengan cara dapat mengidentifikasikan terlebih dahulu kerusakan dan kerugian yang ditimbulkan oleh mesin-mesin produksi. Zero Crisis akan tercapai jika perusahaan dapat mencegah terjadinya kerusakan mesin secara terus-menerus. Zero Defect akan tercapai jika perusahaan dapat meningkatkan efektivitas [1].

Total Productive Maintenance (TPM) adalah penerapan pemeliharaan yang sering dilakukan dalam perusahaan manufaktur. Tingkat keberhasilan penerapan Total Productive Maintenance (TPM) diukur dengan menggunakan metode Overall Equipme Effectiveness (OEE). Pengukuran Overall Equipment Effetiveness (OEE) dilakukan berdasarkan ketiga kategori six big losses, yaitu nilai availability, nilai performance, dan nilai quality. Nilai Overall Equipment Effetiviness (OEE) yang didapatkan lalu dibandingkan dengan nilai Overall Equipment Effetiviness (OEE) dari peralatan dalam kondisi ideal yang merupakan standar dari perusahaan kelas dunia, untuk mengetahui tingkat keberhasilan penerapan Total Productive Maintenance (TPM) [2].

Beberapa literature menyebutkan Overall Equipment Effetiviness (OEE) 50\% merupakan besaran yang dapat diterima. Meskipun demikian, agar menjadi perusahaan yang menguntungkan disarankan untuk memiliki nilai Overall Equipment Effetiviness (OEE) sebesar minimal 84,66\% dengan komposisi faktor Overall Equipment Effetiviness (OEE) seperti pada Tabel 1 [3].

Tabel 1. Standar Nilai OEE

\begin{tabular}{ll}
\hline \multicolumn{1}{c}{ Faktor } & \multicolumn{1}{c}{ Nilai } \\
\hline Availability Rate $(A)$ & $\geq 90 \%$ \\
Performance rate $(P)$ & $\geq 95 \%$ \\
Rate of Quality $(R)$ & $\geq 99 \%$ \\
OEE & $\geq 84,66 \%$ \\
\hline
\end{tabular}

Failure Mode and Effect Analysis (FMEA) mempunyai tujuan untuk mengklasifikasikan kegagalan yang terjadi sesuai dengan nilai Risk Priority Number (RPN) [4]. Analisis lanjut terhadap hasil perhitungan Overall Equipment Effetiviness (OEE) menggunakan metode Failure Mode and Effect Analysis (FMEA). Langkah-langkah penggunaan Failure Mode and Effect Analysis (FMEA) [2]: 
1. Membuat urutan proses produksi pada mesin cetak untuk mengetahui jenis aktivitas yang berlangsung mulai dari masuknya bahan baku hingga dihasilkannya sebuah produk.

2. Mengidentifikasi masalah menggunakan diagram Ishikawa, yang dilakukan dengan mengidentifikasi permasalahan yang terjadi selama proses produksi. Permasalahan yang didapatkan dijabarkan untuk mengetahui akar permasalahannya dengan menggunakan diagram Ishikawa.

3. Memberikan pembobotan, dimana masalah atau kegagalan yang telah didapat dimasukkan kedalam form Failure Mode and Effect Analysis (FMEA). Kemudian dicari efek dari kegagalan tersebut untuk diberi pembobotan pada faktor severity (faktor yang meninjau tingkat efek dari permasalahan). Selanjutnya dicari faktor penyebab terjadinya kegagalan tersebut dan dilakukan pembobotan untuk faktor occurence (faktor yang meninjau frekuensi permasalahan tersebut terjadi) dan detectability (faktor yang meninjau respon yang dapat diberikan untuk mendeteksi kegagalan tersebut).

4. Menghitung nilai Risk Priority Number (RPN) dan penentuan ranking, yang didapatkan dari hasil perkalian ketiga faktor yang telah diberi pembobotan. Akar permasalahan yang mendapat nilai Risk Priority Number (RPN) terbesar akan menjadi prioritas utama untuk diselesaikan. Berikut merupakan rumus yang digunakan untuk perhitungan Risk Priority Number (RPN):

$$
R P N=\text { Severity } x \text { Occurrence } x \text { Detecability }
$$

Berdasarkan uraian tersebut maka dalam penilitian ini digunakan metode Overall Equipment Effectiveness (OEE) dan metode Failure Mode and Effect Analysis (FMEA). Menghitung Overall Equipment Effectiveness (OEE) berdasarkan 3 komponen utama yaitu Avaibility Rate, Performance Rate, dan Quality Rate. Membandingkan hasil perhitungan Overall Equipment Effectiveness (OEE) pada periode April-Juni tahun 2016 dengan periode April-Juni tahun 2017, membuat fishbone diagram untuk mencari akar permasalahannya. Menggunakan metode FMEA dengan 3 variabel utama antara lain severity, occurance, dan detection.

\section{METODE PENELITIAN}

Dalam penelitian ini yang dijadikan objek penelitian adalah mesin Perfect Binding yang digunakan pada industri percetakan, perusahaan percetakan yang diteliti berada di daerah Jakarta.

Metode observasi digunakan dalam penelitian ini untuk mengamati atau meninjau langsung proses produksi pada perusahaan. Selanjutnya dilakukan pengamatan terhadap pencataatan data mesin Perfect Binding. Data yang diamati dalam penelitian ini terdiri dari data output produksi, data mesin, data reject pada proses produksi, data downtime, dan data Operatinmg Time.

\section{Teknik Analisis Data}

Untuk menganalisis permasalahan yang ada pada mesin Perfect Binding digunakan metode Overall Equipment Effectiveness (OEE) dan Failure Mode and effect Analysis (FMEA).

\section{Avaibility}

Tahap ini bertujuan untuk mendifinisikan masalah pemanfaatan waktu untuk kegiatan operasi mesin maupun peralatan, yang ditentukan oleh perusahaan dalam menghasilkan produktivitas hasil produksi yang baik. Dengan rumus sebagai berikut: 


$$
\text { Availability }=\frac{\text { operating Time }}{\text { Planned Production }} \times 100 \%
$$

\section{Performance}

Tahap ini bertujuan untuk menganalisis data seberapa mana mesin menghasilkan produk per jam berdasarkan catatan penelitian secara langsung diruang lingkup hasil produksi (packing) perusahaan. Dengan rumus sebagai berikut:

$$
\text { Performance }=\frac{(\text { Total Product: } \text { Operating Time })}{\text { Ideal } \text { Run Rate }} X 100 \%
$$

\section{Quality}

Tahap ini bertujuan untuk menganalisis kualitas produk yang sesuai standar. Dengan rumus sebagai berikut:

$$
\text { Quality }=\frac{\text { Good Output }}{\text { Actual Output }} \times 100 \%
$$

\section{Overall Equipment Effectiviness (OEE)}

Metode Overall Equipment Effectiveness (OEE) adalah total pengukuran terhadap performance yang berhubungan dengan Avaibility, Performance, dan Quality. Dengan rumus sebagai berikut:

$$
\text { OEE }=\text { Availability }(\%) \times \text { Performance }(\%) x \text { Quality }(\%)
$$

\section{FMEA (Failure Mode and Effect Analysis)}

Dipergunakan setelah mendapatkan faktor yang mempengaruhi kegagalan atau kecacatan dengan tujuan didapatkan faktor mana yang memerlukan penanganan lebih lanjut. Dengan melihat analisa Failure Mode and Effect Analysis (FMEA), dapat diketahui penyebab potensial yang memerlukan tindakan perbaikan segera. Nilai Risk Priority Number (RPN) didapat dari hasil perkalian nilai Severity, Occuranse, dan Detection, kemudian dari hasil nilai tertinggi akan menjadi acuan untuk usulan tindakan perbaikan. RPN tertinggi akan dijadikan usulan tindakan perbaikan.

\section{HASIL DAN PEMBAHASAN}

Untuk mengetahui akar masalah dalam penelitian ini telah dilakukan pengamatan downtime pada mesin perfect binding. Berikut merupakan jenis-jenis downtime pada mesin perfect binding yang dapat dilihat pada Tabel 2.

\begin{tabular}{cl} 
Tabel 2. Jenis Downtime Mesin Yoshino \\
\hline Kode & Jenis Downtime \\
\hline 01 & Persiapan Job/Setting Mesin \\
02 & Kocok/Rapikan Kertas \\
03 & Ganti ukuran \\
05 & Problem Mesin \\
06 & Problem Job \\
08 & Tunggu Acc \\
09 & Mati Listrik \\
10 A & Perbaikan Mesin \\
10 C & Tunggu Spare Part \\
14 & Tunggu Bak Cair \\
16 & Tunggu Bahan \\
17 & Ganti Benang/Kawat \\
\hline
\end{tabular}




\section{Analisis Pengukuran Nilai OEE}

Nilai avaibility akan mencerminkan seberapa besar waktu planned production yang tersedia untuk waktu produksi, berikut merupakan perbandingan nilai avaibility selama 3 bulan (April, Mei, Juni) pada 2016 dan 2017 yang dapat dilihat pada Gambar 1.

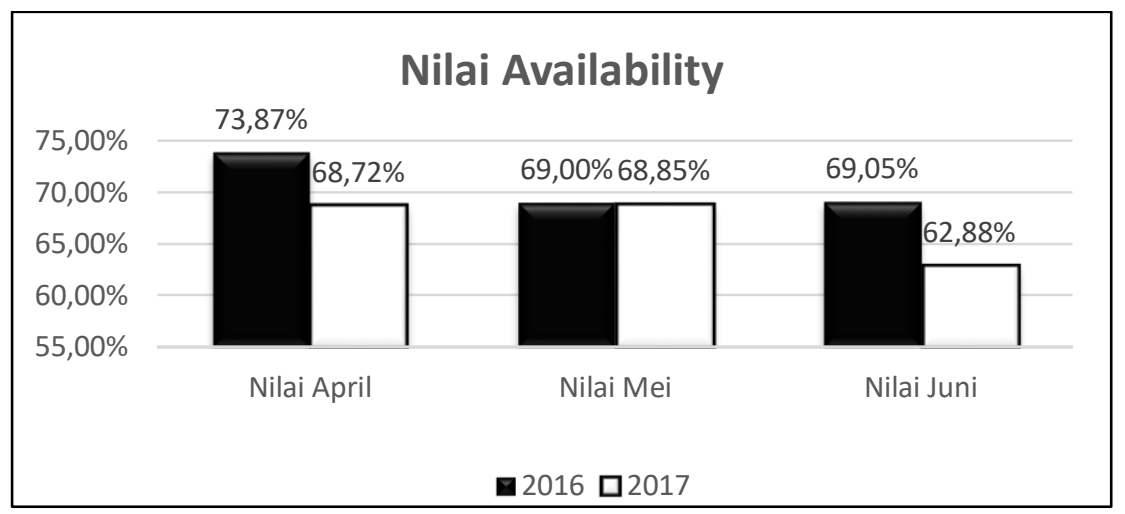

Gambar 1. Nilai Avaibility Mesin Perfect Binding

Dari Gambar 1 di atas telah terjadi penurunan nilai avaibility pada bulan April 2017 sebesar 5,15\%, bulan Mei 2017 sebesar 0,15\%, dan bulan Juni 2017 sebesar 6,17\% dibandingkan dengan tahun sebelumnya yaitu bulan April, Mei, Juni tahun 2016. Pada standar dunia nilai avaibility yaitu $>90,0 \%$, sedangkan nilai avaibility mesin perfect binding pada penelitian ini masih dibawah standar untuk pengukuran nilai Overall Equipment Effectiveness (OEE).

\section{Analisis Nilai Performance}

Nilai performance akan menunjukkan kecepatan ideal (mesin Perfect Binding dalam memproduksi setiap menit untuk menghasilkan barang) berdasarkan kapasitas produksi,. Berikut merupakan perbandingan nilai performance selama 3 bulan (April, Mei, Juni) pada 2016 dan 2017 yang dapat dilihat pada Gambar 2.

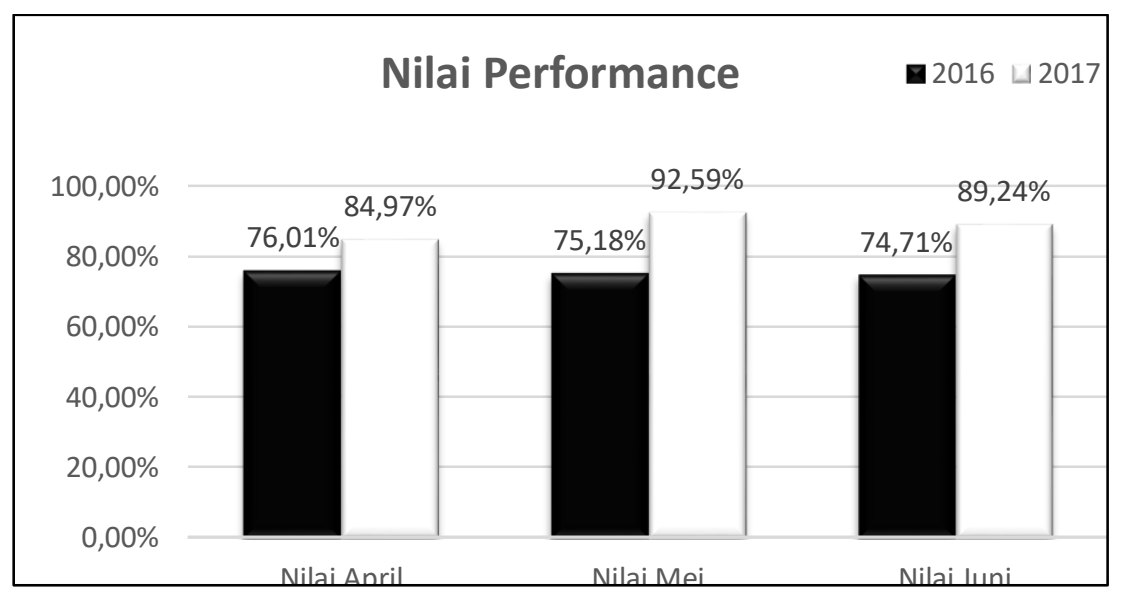

Gambar 2. Nilai Performance Mesin Perfect Binding

Dari Gambar 2 di atas telah terjadi peningkatan nilai performance pada bulan April 2017 sebesar 8,96\%, bulan Mei 2017 sebesar 17,41\% dan bulan Juni 2017 sebesar 14,53\% dibandingkan dengan tahun sebelumnya yaitu bulan April, Mei, Juni tahun 2016. Pada standar dunia nilai performance yaitu $>95,0 \%$, sedangkan nilai performance mesin perfect binding pada penelitian ini masih di bawah standar untuk pengukuran nilai Overall Equipment Effectiveness (OEE). 


\section{Analisis Nilai Quality}

Nilai quality pada penelitian ini terdapat tiga data yaitu total product (total produksi selama 12 jam atau sebanyak 2 shift yang diproduksi), reject product (hasil produksi yang mengalami kecacatan yang nantinya tidak masuk dalam nilai standar produksi), dan good product (didapat dari total product dikurangi reject product yang hasilnya akan diketahui produk yang sesuai dengan standar). Berikut merupakan perbandingan nilai quality selama 3 bulan (April, Mei, Juni) pada 2016 dan 2017 yang dapat dilihat pada Gambar 3.

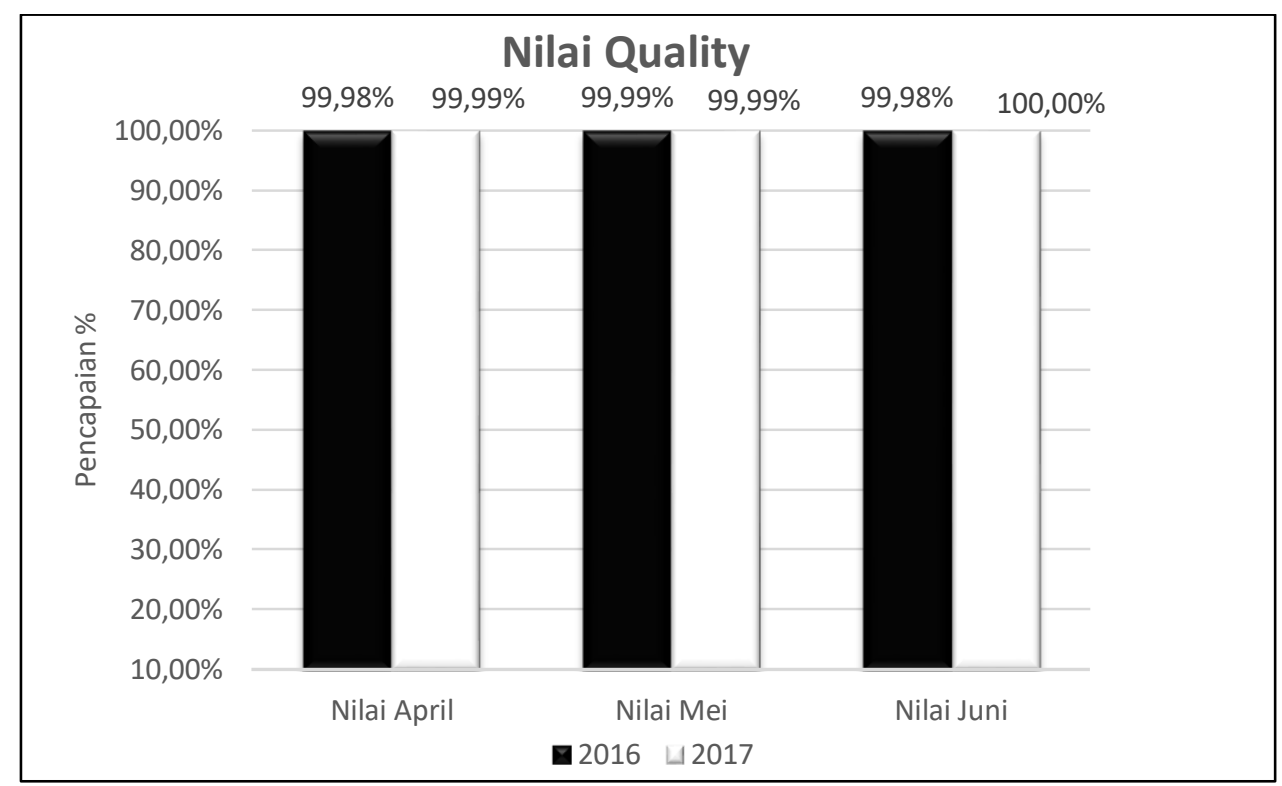

Gambar 3. Nilai Quality Pada Mesin Perfect Binding

Dari Gambar 3 di atas nilai quality mesin Perfect Binding pada penelitian ini sudah mencapai standar untuk pengukuran nilai Overall Equipment Effectiveness (OEE) yaitu $>99,9 \%$.

\section{Analisis Pengukuran Nilai Overall Equipment Effectiveness (OEE)}

Nilai Overall Equipment Effectiveness (OEE) merupakan total pengukuran mesin perfect binding terhadap performance yang berhubungan dengan Avaibility, Performance, dan Quality. Berikut merupakan perbandingan nilai Overall Equipment Effectiveness (OEE) selama 3 bulan (April, Mei, Juni) pada 2016 dan 2017 yang dapat dilihat pada Gambar 4.

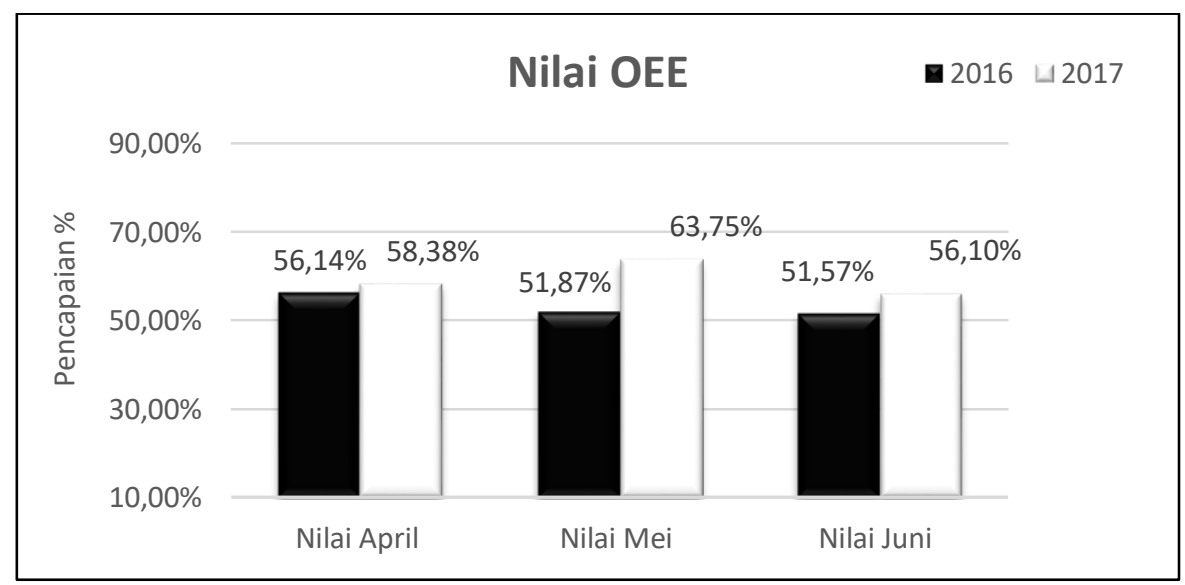

Gambar 4. Nilai OEE Pada Mesin Perfect Binding 
Dari Gambar 4 di atas nilai Overall Equipment Effectiveness (OEE) mengalami peningkatan pada bulan April 2017 sebesar 2,24\%, bulan Mei 2017 sebesar 11,88\%, dan bulan Juni 2017 sebesar 4,53\% dibandingkan dengan tahun sebelumnya yaitu bulan April, Mei, Juni tahun 2016. Nilai Overall Equipment Effectiveness (OEE) maksimal didapatkan pada bulan Mei 2017 yaitu sebesar 63,75\%, nilai tersebut belum mencapai standar nilai ideal Overall Equipment Effectiveness (OEE) yaitu sebesar $>85 \%$.

\section{Analisis Akar Permasalahan}

Dari hasil nilai Overall Equipment Effectiveness (OEE) yang didapat selanjutnya dilakukan analisis menggunakan Fishbone Diagram pada Gambar 5 di bawah ini untuk mengetahui penyebab rendahnya nilai Overall Equipment Effectiveness (OEE).

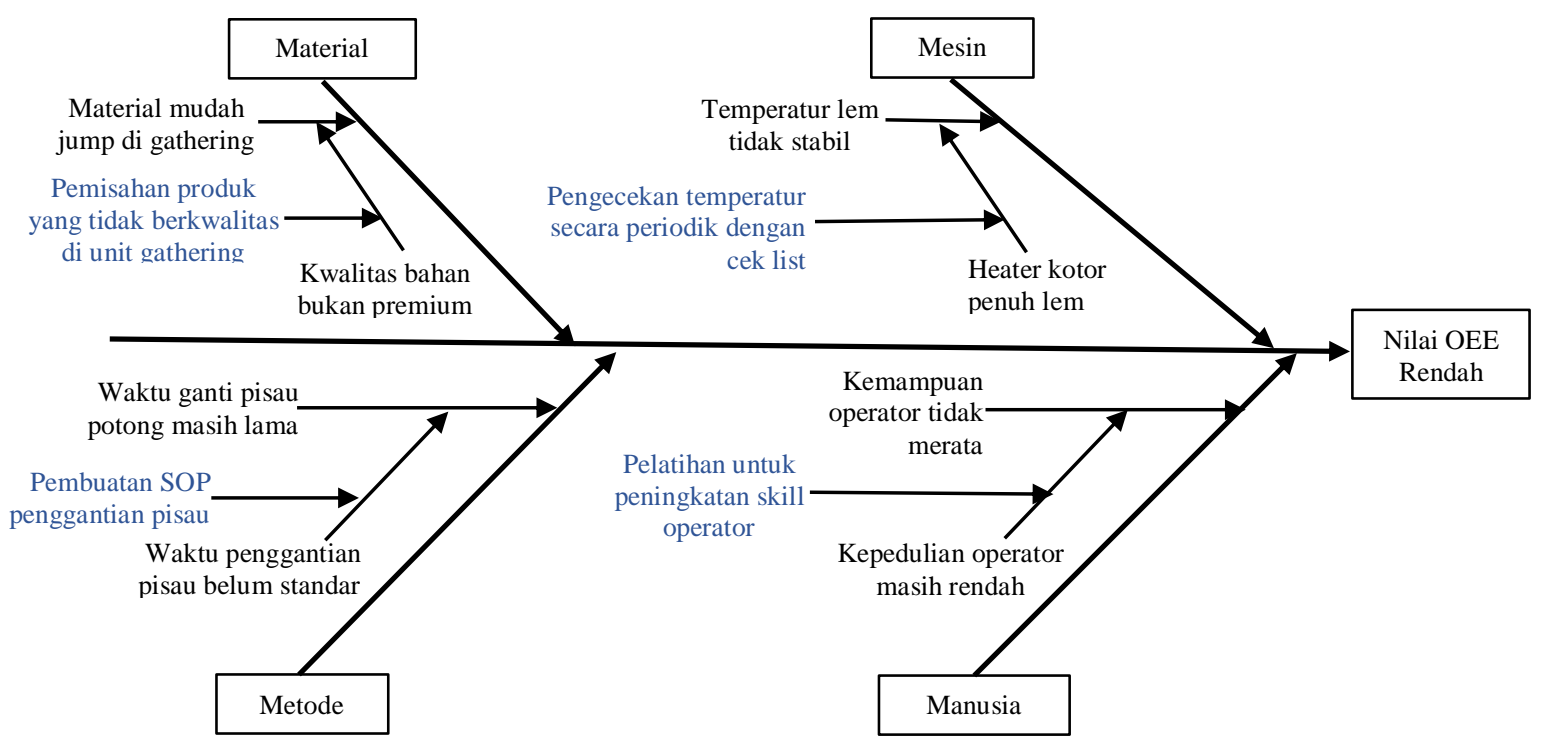

Gambar 5. Gambar diagram sebab akibat fishbone

Mesin: Berdasarkan hasil analisa dan data mesin Perfect Binding, belum adanya jadwal perawatan heater menyebabkan heater kotor sehingga membuat temperatur lem tidak stabil. Maka dalam faktor mesin dapat disimpulkan bahwa waktu yang terbuang dalam 3 bulan pengamatan sebesar 10.137 menit $(168,95$ jam) jika dipresentasikan sebesar $47,66 \%$ dari total downtime.

Metode: Berdasarkan data bahwa belum dilakukannya perhitungan waktu penggantian pisau menyebabkan standar waktu pergantian pisau tidak efisien. Maka dalam faktor metode dapat disimpulkan bahwa waktu yang terbuang dalam 3 bulan pengamatan sebesar 4.135 menit (68,92 jam) jika dipresentasikan sebesar 19,44\% dari total downtime.

Manusia: Berdasarkan hasil analisa data, belum adanya jadwal training atau belum diajukannya training, menyebabkan pengetahuan operator tetang mesin perfect binding belum merata.

Material: Berdasarkan hasil analisa, bahwa keterlambatan vendor supply menyebabkan memakai bahan kualitas bukan premium (grade kedua) sehingga material mudah jump di gathering.

\section{Analisis FMEA}

Berikut ini adalah hasil analisis Failure Mode and Effect Analysis (FMEA) yang diperoleh dari hasil pengolahan diagram Sebab Akibat (fishbone), kemudian diolah dalam perhitungan Failure Mode and Effect Analysis (FMEA). Severity (S), Occurance (O), dan detection (D) didefinisikan dari hasil brainstorming dengan bagian produksi perusahaan. 
Setelah diperoleh nilai perkalian dari SOD maka melangkah ke tahap berikutnya yaitu menentukan Risk Priority Number (RPN). Kemudian nilai Risk Priority Number (RPN) tertinggi dijadikan sebagai acuan prioritas tindakan perbaikan yang harus segera dilakukan. Dari Tabel 3, Analisis Failure Mode and Effect Analysis (FMEA), ada rencana perbaikan dari 3 nilai Risk Priority Number (RPN) yang tertinggi. Pertama adalah untuk mengatasi temperatur bak lem yang tidak stabil, maka rencana perbaikannya adalah dengan cara melakukan pengecekan temperatur oleh operator dengan menggunakan cek list pengecekan temperatur secara periodik. Kedua adalah mengatasi material mudah jump di unit gathering, rencana perbaikannya adalah melakukan pemisahan produk yang tidak berkualitas sebelum ditempatkan di unit gathering. Ketiga adalah waktu ganti pisau yang masih lama, rencana perbaikannya adalah dibuat SOP/Instruksi kerja cara penggantian pisau potong supaya waktu yang digunakan lebih efisien. Untuk lebih lengkapnya Analisis Failure Mode and Effect Analysis (FMEA) dapat dilihat pada Tabel 3:

Tabel 3. Analisis Failure Mode and Effect Analysis (FMEA)

\begin{tabular}{|c|c|c|c|c|c|c|}
\hline $\begin{array}{l}\text { Faktor } \\
\text { Utama }\end{array}$ & $\mathbf{S}$ & Sebab Proses Buruk & $\mathbf{O}$ & Rencana Perbaikan & D & RPN \\
\hline \multirow{2}{*}{ Mesin } & 8 & Temperatur bak lem tidak stabil & 8 & $\begin{array}{l}\text { Melakukan pengecekan terhadap } \\
\text { temperatur secara periodik }\end{array}$ & 8 & 512 \\
\hline & 6 & Heater kotor penuh dengan lem & 7 & $\begin{array}{l}\text { Dilakukan pembersihan secara } \\
\text { berkala }\end{array}$ & 6 & 252 \\
\hline \multirow{2}{*}{ Manusia } & 5 & $\begin{array}{l}\text { Kemampuan operator belum } \\
\text { merata }\end{array}$ & 7 & $\begin{array}{l}\text { Memberikan pelatihan untuk } \\
\text { peningkatan skill operator }\end{array}$ & 4 & 140 \\
\hline & 6 & $\begin{array}{l}\text { Masih kurangnya kepedulian } \\
\text { operator terhadap mesin }\end{array}$ & 4 & $\begin{array}{l}\text { Meningkatkan kontrol terhadap } \\
\text { kinerja operator }\end{array}$ & 5 & 120 \\
\hline \multirow[b]{2}{*}{ Metode } & 7 & $\begin{array}{l}\text { Waktu ganti pisau potong } \\
\text { masih lama }\end{array}$ & 6 & $\begin{array}{l}\text { Dibuat SOP/Instruksi Kerja cara } \\
\text { penggantian pisau potong }\end{array}$ & 7 & 294 \\
\hline & 6 & $\begin{array}{l}\text { Belum ada waktu standar } \\
\text { penggantian pisau }\end{array}$ & 5 & $\begin{array}{l}\text { Menentukan standar waktu } \\
\text { penggantian pisau berdasarkan } \\
\text { banyaknya output yang dihasilkan }\end{array}$ & 5 & 150 \\
\hline \multirow[t]{2}{*}{ Material } & 7 & $\begin{array}{l}\text { Material mudah jump di unit } \\
\text { gathering }\end{array}$ & 7 & $\begin{array}{l}\text { Melakukan pemisahan produk yang } \\
\text { tidak berkualitas sebelum } \\
\text { ditempatkan di unit gathering }\end{array}$ & 7 & 343 \\
\hline & 6 & $\begin{array}{l}\text { Kualitas bahan baku bukan } \\
\text { yang premium }\end{array}$ & 6 & $\begin{array}{l}\text { Mengganti bahan baku yang } \\
\text { kwalitasnya lebih bagus }\end{array}$ & 5 & 180 \\
\hline
\end{tabular}

\section{KESIMPULAN}

Dalam penelitian ini telah dilakukan perhitungan Overall Equipment Effetiviness (OEE) pada Mesin perfect binding, pada periode April-Juni 2016 yang dibandingkan dengan periode April-Juni 2017, didapatkan hasil pada bulan April 2017 sebesar 58,38\%, pada bulan Mei 2017 sebesar 63,75\%, dan di bulan Juni 2017 sebesar 56,10\% secara umum pencapaian Overall Equipment Effetiviness (OEE) meningkat disetiap bulannya, tetapi belum mencapai kriteria World Class Overall Equipment Effetiviness (OEE). Terjadi peningkatan di bulan April 2017 sebesar 2,24\%, di bulan Mei 2017 sebesar 11,88\%, dan di bulan Juni 2017 sebesar 4,53\% jika dibandingkan dengan periode April-Juni 2016.

Rendahnya nilai Overall Equipment Effetiviness (OEE) yang didapatkan pada mesin Perfect Binding menyebabkan produktivitas mesin tersebut menurun, berikut adalah 3 rencana perbaikan berdasarkan nilai Risk Priority Number (RPN) tertinggi dari analisis Failure Mode and Effect Analysis (FMEA), pertama untuk mengatasi temperatur bak lem yang tidak stabil, dengan melakukan pengecekan temperatur secara periodik. Kedua untuk mengatasi material mudah jump di unit gathering, dengan melakukan pemisahan produk yang tidak berkualitas sebelum ditempatkan di unit gathering. Ketiga untuk mengatasi ganti pisau yang masih lama, rencana perbaikannya adalah dibuat SOP/Instruksi kerja. 


\section{DAFTAR PUSTAKA}

[1].Kuncahyo, D. S. 2015. Pendekatan Penerapan Total Productive Maintenance (Tpm) Di Stasiun Press Palm Oil Pada Mesin Digester Dan Mesin Press PT. Bangkitgiat USAha Mandiri Dengan Menggunakan Indikator Oee Dan Metode Fmeca (Failure Mode Effect and Critical Analysis). Penelitian dan Aplikasi Sistem dan Teknik Industri, 8(3).

[2].Bilianto, B. Y., \& Ekawati, Y. 2017. Pengukuran Efektivitas Mesin Menggunakan Overall Equipment Effectiveness untuk Dasar Usulan Perbaikan. Jurnal Ilmiah Teknik Industri, 15(2), 116-126.

[3].Rosyidi, K., Santoso, P. B., \& Sasongko, M. N. 2015. Peningkatan Efektivitas Perawatan Mesin Perontok Bulu Unggas Dengan Metode Overall Equipment Effectiveness dan Failure Mode Effect Analysis (Studi Kasus di Perusahaan Pengolahan Ayam Kampung Pasuruan). Journal of Engineering and Management in Industrial System, 3(2).

[4].Jannah, R. M., Supriyadi, S., \& Nalhadi, A. 2017. Analisis Efektivitas Pada Mesin Centrifugal Dengan Menggunakan Metode Overall Equipment Effectiveness (OEE). In Prosiding Seminar Nasional Riset Terapan| SENASSET (pp. 170-175). 